\title{
Research Paper: Structured Pattern for Parental Stress Based on Self-Conscious Affect and Family Performance of Children With Autism
}

\author{
Monir Kalantar Ghoreishi' ${ }^{1} \mathbb{0}$, Hassan Asadzadeh ${ }^{2 *}$ [C, Khadijeh Abolmaali Hosseini ${ }^{3}$ \\ 1. Department of Psychology, Science and Research Branch, Islamic Azad University, Tehran, Iran. \\ 2. Department of Educational Psychology, Faculty of Psychology and Education, Allameh Tabataba'i University, Tehran, Iran. \\ 3. Department of Psychology, Faculty of Psychology and Humanities, Roodhen Branch, Islamic Azad University, Tehran, Iran.
}

\begin{tabular}{|c|c|}
\hline $\begin{array}{l}\text { Use vour device to scan } \\
\text { and read he article online }\end{array}$ & Critat on Kalantar Ghoreishi M, Asadzadeh H, Abolmaali Hosseini Kh. Structured Pattern for Parental Stress Based on Self- \\
\hline 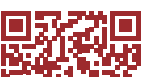 & $\begin{array}{l}\text { Conscious Affect and Family Performance of Children With Autism. Journal of Modern Rehabilitation. 2018; 12(3):201-208. } \\
\text { http://dx.doi.org/10.32598/JMR.V12.N3.201 }\end{array}$ \\
\hline $1+4+4$ & doij http://dx.doi.org/10.32598/JMR.V12.N3.201 \\
\hline
\end{tabular}

(c) (i) (5)

Article info:

Received: 07 Jan 2018

Accepted: 25 Jun 2018

Available Online: 01 Jul 2018

\section{Keywords:}

Parental stress, Shame \& guilty feeling, Family performance, Autism Spectrum Disorder (ASD)

\section{A B S TRACT}

Introduction: Developmental disorders consist of a broad spectrum of chronic and life-long disorders resulted from mental or physical deficits; therefore, they may affect daily experiences. The current study aimed at evaluating parental stress modeling based on self-conscious affect (shame and guilt) of parents and family performance. It was considered a correlational study based on structural equations modeling.

Materials and Methods: Statistical population consisted with all mothers of children with autism spectrum disorders studied in the autistic schools in Tehran. In the current study, 250 mothers of children with autism spectrum disorders were selected by random convenience method, then they were evaluated by parental stress index-short form, test of self-conscious affect, and family performance questionnaire. Data were analyzed with SPSS version 24 and AMOS 23.

Results: Findings of the study suggested that $51 \%$ of parental stress was explained by selfconscious affect (shame and guilt) of parents as well as family performance. Also, indirect way of self-conscious affect (shame and guilt) of parents, with mediating family performance on parental stress, was supported given to maximum leveling and as general, this model was supported.

Conclusion: The current study results showed that focusing on self-conscious affect (shame and guilt) of parents as well as family performance and also emphasizing on parental stress of parents with autistic child and coping strategies may have significant effects on decreasing the stress and vulnerability of this population. 


\section{Introduction}

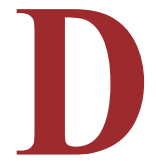

evelopmental disorders consist of a broad spectrum of chronic and life-long disorders resulted from mental or physical deficits; therefore, they may affect daily experiences such as language, learning, activity, self-help and skills of independent life [1]. Various common developmental problems are as follow: autism spectrum disorder, Down syndrome, intellectual disability, vision problems, cerebral palsy and deafness, but they are not limited to theses groupings. Autism Spectrum Disorder (ASD) is a group of developmental complicated disorders characterized by delay or problems in cognitive, social, emotional, language, sensory and motor abilities. The increasing prevalence of this disorder in the last three decades (one out of 88 birth) made great researches in the field of recognizing biological, genetics, and symptoms related to etiology and causes of ASD [1].

Great studies supported that physical and emotional competence related to raising a child with autism put parents under heavy pressure [2]; parents not only experience more depression, worry, stress, shame, and shyness but also feel fewer integration, meaningfulness, and hope [3]. There are considerable varieties of ways to adapt with stress-evoking conditions in these families [4, 5]; therefore, some families consider this child as difficult and harsh, while some others adapt to the conditions, and even experience positive consequences, and may have functions similar to those of healthy families $[6,7]$.

According to family stress theory, existing resources play important roles in helping parents to cope with high stress conditions [1]. In Perry stress model (2004) these resources are divided into individual and family groups both are considered as important elements that may affect the relationship between a child with developmental disability and positive and negative results for parents [8]. Hence, it can be said that selfconscious affect is one of components of intra personal elements and may have effects on personal resources under stressful situations for family.

Self-conscious feelings include shame and guilt related to self. In order to feel such emotions, a set of standards should be established to evaluate behavior [9]. In fact everyone has a capacity to get experiences of the two emotions. The feeling of guilt is described based on failure; therefore, one feels anxiety, fear and worry and also feels a need to compensate by a behavior that breaks inner ethics standards. In describing guilt, the focus is on behavior. In the feeling of shame, the focus is on "self" as a whole element. In this way, shame is defined as the emotion based on depressive feelings such as hopelessness, silliness, and the desire to avoid others due to the fear of rejection [10-12]. Studies showed that the feelings of shame and guilt are related to psychological stress [13].

It is believed that since families that have a child with ASD experience severe stress and distress, to help them adapt with their conditions, in addition to paying special attention toward both physical and psychological problems, early interventions are necessary for the whole family since the whole family is involved in dilemma and a good performance of family is recognized as a buffer against parental stress [14].

Family performance in comparison to poor skills of children may strongly predict parental stress [15]. Other studies suggested that raising a child with ASD has negative effects on family performance and relationship out of family $[16,17]$. On the other hand, other studies suggested that family performance is considered as a risk factor for stress; a family with an ASD child has no more stress than other families and performance of these families are relatively good [18]. In general, family powerful ness and quality of life of parents with autistic child are affected by different components of family performance and other family features [19].

In this regard, it was shown that main stressors are motor and behavioral disorders of child and a good family performance is considered as a buffer against such stresses [14]. In addition, parental positive views are related to low parental stresses. It was suggested that there are significant differences between parental stress and functions of a family with ASD child and those of a family with normal child [20]. Parental stress in mothers of an ASD child is more than that of mothers of normal child and their performances are lower than mothers of a normal child.

One of the models that may explain how to cope with stress is conceptual model of disability-stress-coping suggested by Wallander et al. [21].This model, considering buffer agents against stress resulted from having a child with developmental disability, distinguishes adjustable families and non- adjustable families [22]. Conceptual model of Wallender and Varni (1989) was employed [22] to examine adaptation in children with chronic disease ,Greenspan added family cope [23], and Wallender and Varni added cognitive evaluation [24] to this model risk factors of disease and psychological 


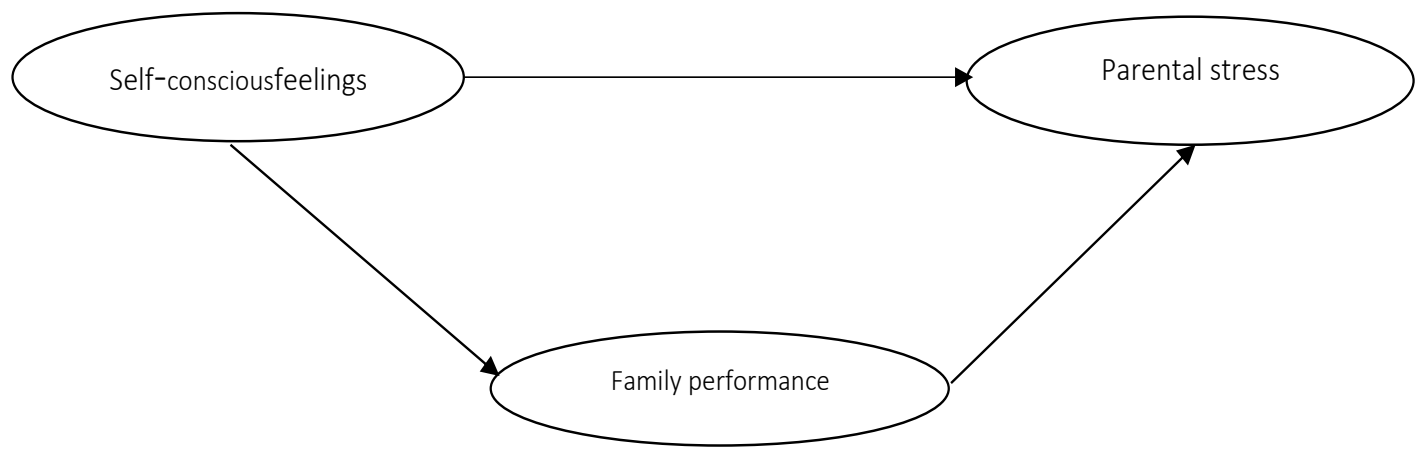

Figure 1. Conceptual model of parental stress

stress, reinforcement factors, inter components, social environment and stress processing are involved in this revised model [20]. This model was employed by different studies including [7] that studied this model for mothers of children with rheumatism, [2] that investigated this model for mothers of children with cerebral palsy as well as [6] that used this model for mothers of children with different disabilities.

Relationship between child disorder and family performance is a reciprocal relationship; instead of paying attention to child with special needs, attention should be paid toward families with such children [25] since a child with severe developmental challenges makes family more challenges. Under the influences of changes from raising child with ASD, family functions will be changed and it is necessary to consider the whole family beyond a child. Families with ASD children face some stressors and challenges. Without concentration on family resources significantly decrease, emotional problems increase, useless interactions with the affected child sustain and become inflexible, and consequently, developmental pattern of child fails. But with positive trend of family performance, positive experiences are provided for the child and may facilitate his treatment.

Therefore, presenting such models with addressing related and effective factors on positive changes are necessary and important. Among these, self-consciousness is considered as a factor to help with the child managing conditions and family performance resulted from rational and affective relationships among members recognized as effective factor against parental stress and addressing them are important. Therefore, presenting effective models to consider factors effective on parental stress for ASD children parent clarifies the necessity of the current study.

According to the research problem, the current study aimed at presenting the structural pattern for parental stress of autistic children based on the relationship be- tween self-conscious affects (shame and guilt) with the mediator role of family performance to make changes in effective factors through intervention and effective training, then to contribute decreasing parental stress as well as to improve parents mental health.

\section{Materials and Methods}

\section{Research design}

The current study was fundamental in terms of objectives, cross sectional in terms of data gathering method, descriptive in terms of analysis of data, and correlational in terms of structural equations modeling. After gathering data, in descriptive statistics data were analyzed by means, standard deviation in terms of central tendency index and distribution index and in inferential statistics by structural equations modeling and; SPSS version 24 , and AMOS 24 were employed.

Statistical population of the study was all 450 families with ASD children in Tehran that had recorded history in Tehran Autism Association. Then, after promising to keep the personal information confidential by researchers and getting written consent of the families, 250 mothers of ASD children were selected through available sampling method and they completed three questionnaires.

\section{Research tools}

Research tools included the following three questionnaires that their validities were evaluated and confirmed in samples through measurement model.

\section{Test of Self-Conscious Affect (TOSCA-2)}

This questionnaire is a self- measure tool in which 16 situations (scenarios) are presented to subjects and subjects should rate feeling, emotional and behavioral responses, and their possibility based on five-point 
Likert scales. All scenarios have items related to mental involvement of shame and guilt. Low scores suggest low guilt feeling and high scores show high shame and guilt feeling [24]. One Study reported the validity of two scales in a satisfactory range [10].In Iran, formal validity was approved by consultants and psychology professors [26]. In the study by Fergusen, Cronbach alpha coefficient was reported 0.81 for shame and 0.78 for feeling guilt. In a study by Anooshi, results of test-retest of this tool after four weeks were 0.78 and 0.70 , respectively $[26,27]$.

\section{Family Performance Questionnaire}

This questionnaire contains 60 questions to examine family performance and was written based on the McMaster pattern [28]. This questionnaire has two forms of 53 and 45 items. Subjects respond to the questions based on a five-point Likert scale "completely agree, completely disagree" for each item (completely agree: 1, agree: 2 , completely disagree: 3 , disagree: 4 ). Members of family up to 12 years old can complete this questionnaire. High scores suggest unhealthy function. This tool has six sub scales: problem solving, communication, role, affective responsive, affective combination, behavior control, and a score as total function.

All seven scales have considerable internal consistency (Cronbach's alpha coefficient, 0.72 to 0.92 ). Validity and re-test reliability was satisfactory during one week (0.66 to 0.76$)$. In Iran, reported internal consistency were 0.65 for problem-solving, 0.54 for communication, 0.51 for role, 0.68 for affective responsive and affective combination, 0.64 for behavior control, and 0.84 for total performance [29].

\section{Parental Stress Index-Short Form (PSI-SF)}

This tool contains 36 questions on parental stress developed by Abidin and it measures three subscales of parental distress, ineffective interaction of parent-child and characteristics of the problem making child [30]. In scoring these indices it should be noted that questions of sub scales are not ordered and questions are distributed in the whole questionnaire and not all questions have the same scores. Internal stability was reported as good in a study [31] and suggested that the three-factor model was good enough to describe data. Also, a study approved internal stability and model fit [32].

In a study in Iran, validity of total score of parental stress and also of parental distress, ineffective interaction of parent-child, and characteristics of the problem making child were $0.90,0.80,0.84$, and 0.80 , respectively [26]. Validity coefficient of re-test after 18 days for total score and sub scales were $0.75,0.82,0.73$ and 0.71 that suggested stability in time [33].

\section{Results}

Demographic data (age, marital relationship, and job status) of autistic children mothers are shown in Table 1. To analyze data, modeling of structural regression equations was presented.According to Table 1, most of subjects were in the age range of 26-35 years old and had non-relative marriage and non-governmental jobs.

According to Table 2, root mean square error of approximation equals 0.074 ; therefore, it is less than 0.1 and is acceptable. Root mean square error of model is suitable. Also, $\mathrm{K}^{2}$ freedom degree (2.661) is between 1and 3 so GFI, CFI, and NFI are greater than 0.9 , which means that this model is suitable for variables.

Table 1. Demographic data (age, marital relationship, and job status) of autistic children mothers

\begin{tabular}{cccc}
\hline Variable & Sub-Set & Frequency & Percent of Frequency \\
\hline & $20-25$ & 12 & 4.8 \\
Age (y) & $26-35$ & 177 & 70.8 \\
& $36-40$ & 61 & 24.4 \\
Marital relationship & Relatives & 76 & 30.4 \\
\hline Job status & Non-relatives & 174 & 69.6 \\
& Unemployment & 143 & 57.2 \\
\hline
\end{tabular}


Table 2. Fit indices resulted from data analysis and variables after one-step correction

\begin{tabular}{ccccc}
\hline Name of Test & Description & Acceptable Range & Digit Before Correction & Digit After Correction \\
\hline$\chi^{2} / \mathrm{df}$ & Relative Kayaskoer & $<3$ & 2.73 & 2.661 \\
RMSEA & $<0.1$ & 0.074 & 0.47 \\
\hline GFI & $>0.9$ & 0.883 & 0.952 \\
\hline NFI & $>0.9$ & 0.893 & 0.912 \\
\hline CFI & $>0.9$ & 0.874 & 0.908 \\
\hline DF & - & 58 & 57 \\
\hline
\end{tabular}

$J \mathrm{MR}$

RMSEA: Root Mean Square Error of Approximation; GFI: Goodness of Fit Index; NFI: Normality of Fit Index; CFI: Comparative Fit Index; DF: Degree of Freedom

Table 3. Direct estimation using maximum likelihood accuracy

\begin{tabular}{cccccc}
\hline Variable & $\mathbf{b}$ & $\mathbf{B}$ & $\mathbf{R}^{2}$ & $\mathbf{t}$ & $\mathbf{P}$ \\
\hline $\begin{array}{c}\text { Self-conscious on } \\
\text { parental stress }\end{array}$ & 0.49 & 0.32 & 0.156 & 8.182 & 0.001 \\
$\begin{array}{c}\text { Family performance } \\
\text { on parental stress }\end{array}$ & 0.29 & 0.14 & 0.04 & 7.182 & 0.001 \\
\hline
\end{tabular}

According to Table 3, self-consciousness HAS direct effects on parental stress, all paths of shame and guilt feelings and family performance on parental stress explain 0.156 and 0.04 variance of parental stress. According to Table 4, indirect path of perceived social support, self-differentiation, shame, and feeling guilt with mediator role of family performance are observed. In general, three variables may predict parental stress that $24 \%$ variance of it is explained by these variables and $76 \%$ variance of parental stress is explained by other variables out of the current study.

The final model of standard variables was presented (Figure 1). As findings show, variables can predict parental stress. Also, indirect path of self-consciousness with mediator role of family performance has effects on parental stress; therefore, by maximum likelihood accuracy this model was approved.

\section{Discussion}

The current study aimed at evaluating model fit of structural model of parental stress for parents with autistic children based on self-conscious affects (guilt and shame) with the mediator role of family performance. Findings showed that self-conscious affects had direct and indirect effects on parental stress. These finding were consistent with those of previous studies, that showed good family performance and positive views and emotions were considered as protective factors against stress [18].

As well as, it was found that parental stress in mothers of ASD children was higher than those of mothers of normal children and their performance was lower than those of mothers of normal children [19]. It was clarified that family performance may predict parental stress [15].

Table 4. Indirect estimation of model using maximum accuracy method

\begin{tabular}{cccc}
\hline Variable & $\boldsymbol{\beta}$ Direct Path & $\boldsymbol{\beta}$ Indirect Path & $\mathbf{R}^{\mathbf{2}}$ \\
\hline $\begin{array}{c}\text { Self-conscious affects with } \\
\text { mediator role of family perfor- } \\
\text { mance on parental stress }\end{array}$ & 0.49 & 0.38 & 0.186 \\
\hline
\end{tabular}


It was suggested that raising ASD child may have negative effects on family performance $[16,17]$. In the current study, direct effects of family performance on parental stress were addressed. It is believed that any children need developed family environment to reach favorite development and growth [25]. In other words, if a child wants to reach the necessary developmental skills, family as a systematic and whole unit should get those developmental skills.

In fact, the whole family may pass different developmental stages. Paying attention toward family growth is important since mental problems of child may be resulted from both family and himself [34]. Therefore, family performance may affect parental stress. Similarly, ASD has effects on psychological health of the whole family, and family conflicts may predict expression of autistic symptoms. It was that adaptability of family with child special conditions may affect the behavioral problems of child [35]. Also, they pointed that ASD children may influence family and react to family environment. Therefore, the relationship between disorder of child and family performance in reciprocal relation and family experiences dysfunctions under effects of dynamic disorder of child.

Since families with ASD children experience stress and distress, to improve their adaptability and attention toward physical and psychological problems of child it is necessary to provide early intervention since the whole family is involved in this problem and good family performance is considered a protective factor against parental stress [14].

Another finding was direct effects of self-consciousness on parental stress. Presence of difficult child in family may increase stress of family and may affect the whole family system beyond child nurses. According to previous studies, expression level of positive effects by parents of ASD child is lower than those of the parents of normal child. Parents of ASD children may be involved in child problems and experience negative emotions [35]. Shame and guilt feelings are the effects that they experience [36]. In addition, shame and guilt have relationships with psychological stress [14]. According to the above, experiences of shame and guilt are related to "self" more than other feelings and are provocated by self-reflection and Self-evaluation.

These feelings cover reactions toward features and behaviors. Shame and feeling guilt are resulted from primarily personal recognition of negative views and behaviors toward himself or his relatives (family, friends or peers). One of the ways to distinguish between self-consciousness affects and unconsciousness affects is that intact emotions are expressed as they are or changed by self-processes such as self- reflection and self-evaluation significantly. These processing transform feeling of fear and upset into shame and guilt, which are related to self [37].

Shame and guilt are called moral feelings since they prevent anti-social behaviors. Despite that, in most of the cases, shame and guilt are considered ad similar feelings and even they are interchangeable but theoretical bases and literatures made their differences as prominent. Of course, these feelings are not the same in terms of morality and adaptability. Evidence suggested that while feeling guilt is provocative in a positive way, feeling shame is a moral emotion, which may be negative [38].

Root of feeling guilt should be searched within human relationships and be observed in conceive other people's distress and sadness. Within interpersonal approach in terms of feeling guilt, enthusiasm is emphasized. Different recognition factors are correlated with feeling guilt. Components that predict feeling guilt are: loneliness, shameful relationships, shyness and Assertiveness [39]. In terms of shame, theorists believe that shame function is not only making distress in positive effects since negative feelings such as fear also have such functions. In addition, related researches to shame tried to distinguish between shame and other feelings such as anxiety [40].

Another finding of the current study was indirect effect of shame and guilt feelings on parental stress with mediator role of family performance. Disabilities in doing developmental tasks make family face psychological and affective problems. Some disorders and personality, mood, and behavioral problems originate in neglect in the developmental tasks. All humans need intimation, love, affection, and attention and also, humans should give love to others [6].

According to Mezloo, love and care are fundamental needs and the expression of these feelings is important for family members. Therefore, family view toward itself and its members especially toward autistic child may change mental health of whole family [41]. If family could not meet such needs, its members experience psychological distress; in addition, self-definition in family or member views with the presence of ASD child causes psychological problems for the families [8].

In center of guilt, there are modification techniques/ behaviors, and feelings such as altruism, care, and love. 
According to Btson such feelings influence the relationships among members [38]. Therefore, feeling guilt punishes immoral behaviors and there is time when person violates social norms or predicts violation of social norms, feeling guilt may arise against it $[42,43]$.

Shame is feed within family and has effects on relationship concepts [44]. Humans are social creatures that need trust and reliance. Shame is appeared in the context of breaking trust and support, and has effects on relationships among family members [45]. Therefore, emotions and self-consciousness affects such as shame and guilt have direct effect on family performance and consequently on parental stress.

One of the current study limitations was that the subjects were only mothers in urban areas, and demographic al and health of other members of the families were not considered. The current cross sectional study depended on subjective reports and a few resources for developmental approach; hence, personal differences based on family performance are suggested for future studies.

\section{Ethical Considerations}

\section{Compliance with ethical guidelines}

All ethical principles were considered in this article. The participants were informed about the purpose of the research and its implementation stages. They were also assured about the confidentiality of their information; Moreover, They were allowed to leave the study whenever they wish, and if desired, the results of the research would be available to them.

\section{Funding}

This research did not receive any specific grant from funding agencies in the public, commercial, or not-forprofit sectors.

\section{Authors' contributions}

All authors contributed in designing, running, and writing all parts of the research.

\section{Conflict of interest}

The authors declared no conflict of interest.

\section{References}

[1] Bluth K, Roberson PN, Billen RM, Sams JM. A stress model for couples parenting children with autism spectrum disorders and the introduction of a mindfulness intervention. Journal of Family Theory \& Review. 2013; 5(3):194-213. [DOI:10.1111/jftr.12015] [PMID] [PMCID]

[2] Krstić T, Mihić L, Mihić I. Stress and resolution in mothers of children with cerebral palsy. Research in Developmental Disabilities. 2015; 47:135-43. [DOI:10.1016/j.ridd.2015.09.009] [PMID]

[3] Manor-Benyamini I, Nator M. Terms of stress sense of coherence and hope within the Druze community of Israel. Research in Developmental Disabilities. 2016; 55:358-67. [DOI:10.1016/j. ridd.2016.05.003] [PMID]

[4] Cohen S, Kamarck T, Mermelstein R. A global measure of perceived stress. Journal of Health and Social Behavior. 1983; 24(4):385-96. [DOI:10.2307/2136404] [PMID]

[5] SitiNorIsmalina I, Ismarulyusda I, Azriani AR, NurZakiahMohd S, NormahChe D, SyarifHusin L, et al. Health and quality of life among the caregivers of children with disabilities: A review of literature. Asian Journal of Psychiatry. 2016; 23:71-7. [DOI:10.1016/j.ajp.2016.07.007] [PMID]

[6] Findler L, Jacoby AK, Gabis L. Subjective happiness among mothers of children with disabilities: The role of stress, attachment, guilt and social support. Research in Developmental Disabilities. 2016; 55:44-54. [DOI:10.1016/j.ridd.2016.03.006] [PMID]

[7] Manuel JC. Risk and resistance factors in the adaptation in mothers of children with juvenile rheumatoid arthritis. Journal of Pediatric Psychology. 2001; 26(4):237-46. [PMID]

[8] Perry A. A model of stress in families of children with developmental disabilities: Clinical and research applications. Journal on Developmental Disabilities. 2004; 11(1):1-6.

[9] Zou Z, Wang D. Guilt versus shame: Distinguishing the two emotions from a Chinese perspective. Social Behavior and Personality. 2009; 37(5):601-4. [DOI:10.2224/sbp.2009.37.5.601]

[10] Stuewig J, Tangney JP, Heigel C, Harty L, McCloskey L. Shaming, blaming, and maiming: Functional links among the moral emotions, externalization of blame, and aggression. Journal of Research in Personality. 2010; 44(1):91-102. [DOI:10.1016/j. jrp.2009.12.005] [PMID] [PMCID]

[11] Tangney JP, Wagner P, Gramzow R. Proneness to shame, proneness to guilt, and psychopathology. Journal of Abnormal Psychology. 1992; 101(3):469-78. [PMID]

[12] Ellingsen T, Johannesson M, Tjøtta S, Torsvik G. Testing guilt aversion. Games and Economic Behavior. 2010; 68(1):95-107. [DOI:10.1016/j.geb.2009.04.021]

[13] Stotz SJ, Elbert T, Müller V, Schauer M. The relationship between trauma, shame, and guilt: Findings from a communitybased study of refugee minors in Germany. European Journa of Psychotraumatology. 2015; 6(1):25863. [DOI:10.3402/ejpt v6.25863] [PMID] [PMCID]

[14] Guyard A, Michelsen SI, Arnaud C, Fauconnier J. Family adaptation to cerebral palsy in adolescents: A European multicenter study. Research in Developmental Disabilities. 2017; 61:13850. [DOI:10.1016/j.ridd.2016.11.010] [PMID] [PMCID]

[15] Smith TB, Oliver MNI, Innocenti MS. Parenting stress in families of children with disabilities. American Journal of Orthopsy- 
chiatry. 2001; 71(2):257-61. [DOI:10.1037/0002-9432.71.2.257] [PMID]

[16] Cole DA. Out-of-home child placement and family adaptation: A theoretical framework. American Journal of Mental Deficiency. 1986; 91(3):226-36. [PMID]

[17] Martin CA, Colbert KK. Parenting: A life span perspective. New York: McGraw-Hill; 1997.

[18] Lustig DC. Families with an adult with mental retardation Empirical family typologies. Rehabilitation Counseling Bulletin. 1997; 41(2):138-57.

[19] Mohtashami; Ebrahimi; Ali Akbari Dehkordi M, Chime Narges. [Comparison of parental stress, satisfaction and family functioning in mothers of children with autism and normallydeveloping children (Persian)]. Journal of Exceptional children .2016; 16(4) 51-62.

[20] Wakimizu R, Yamaguchi K, Fujioka H. Family empowerment and quality of life of parents raising children with developmental disabilities in 78 Japanese families. International Journal of Nursing Sciences. 2017; 4(1):38-45. [DOI:10.1016/j. ijnss.2016.12.004]

[21] Wallander JL, Varni JW, Babani L, Banis HT, DeHaan CB, Wilcox KT. Disability parameters, chronic strain, and adaptation of physically handicapped children and their mothers. Journal of Pediatric Psychology. 1989; 14(1):23-42. [DOI:10.1093/ jpepsy/14.1.23] [PMID]

[22] Thompson Jr RJ, Gustafson KE. Adaptation to chronic childhood illness. Washington: American Psychological Association 1996. [DOI:10.1037/10188-000]

[23] Wallander JL, Varni JW. Adjustment in children with chronic physical disorders: Programmatic research on a disability-stresscoping model. In: La Greca AM, Siegel LJ, Wallander JL, Walker CE, editors. Advances in Pediatric Psychology. Stress and Coping in Child Health. New York City: Guilford Press; 1992.

[24] Greenspan S. The developmental approach to family functioning: The historical background of the different ways or lenses or theories- all different ways of looking at families- A very complex process. Maryland: The Floortime Foundation; 2007.

[25] Tangney JP, Dearing R, Wagner PE, Gramzow R. Test of SelfConscious Affect (TOSCA)-3. Fairfax, Virginia: George Mason University Press; 1989.

[26] Sanaiizaker B. [Scales for measuring family and marriage Second edition (Persian)]. Tehran: Besat; 2008.

[27] Anooshei M, Poorshahryari M, Sanaiizaker B. [Examining relationship between female percept of parenting style with shame and guilty potentials in them new and research in consultancy (Persian)]. Journal of Counseling Research .2006; 7(27):20-3.

[28] Epstein NB, Baldwin LM, Bishop DS .The McMaster family assessment device. Journal of Marital and Family Therapy. 1983; 9(2):171-80. [DOI:10.1111/j.1752-0606.1983.tb01497.x]

[29] Ahmadi K, Khodadadi Gh, Anisi J, Abdolmohamadi E. [Problems of Families with Disabled Children (Persian)]. Journal of Military Medicine. 2011; 13(1):49-52.

[30] Abidin RR. Parenting stress index: Professional manual. New York City: Psychological Assessment Resources; 1995.
[31] Reitman D, Currier RO, Stickle TR. A critical evaluation of the Parenting Stress Index-Short Form (PSI-SF) in a head start population. Journal of Clinical Child and Adolescent Psychology. 2002; 31(3):384-92. [DOI:10.1207/S15374424JCCP3103_10] [PMID]

[32] Yeh CH, Chen ML, Li W, Chuang HL. The Chinese version of the parenting stress index: A psychometric study. Acta Paediatrica. 2001; 90(12):1470-7. [DOI:10.1111/j.1651-2227.2001. tb01615.x]

[33] Fadaii Z, Dehghani M, Farhadei F, Tahmasian K. [Investigating reliability, validity and factor structure of parenting stressshort form in mother`s of 7-12 year-old children (Persian)]. Research in Behavioral Sciences. 2010; 8(2):81-91.

[34] Das S, Das B, Nath K, Dutta A, Bora P, Hazarika M. Impact of stress, coping, social support, and resilience of families having children with autism: A North East India-based study. Asian Journal of Psychiatry. 2017; 28:133-9. [DOI:10.1016/j. ajp.2017.03.040] [PMID]

[35] Baker JK, Seltzer MM, Greenberg JS. Longitudinal effects of adaptability on behavior problems and maternal depression in families of adolescents with autism. Journal of Family Psychology.2011; 25(4):601-9. [DOI:10.1037/a0024409] [PMID] [PMCID]

[36] Manor-Binyamini I, Nator M. Parental coping with adolescent developmental disabilities in terms of stress, sense of coherence and hope within the Druze community of Israel. Research in Developmental Disabilities. 2016; 55:358-67. [DOI:10.1016/j. ridd.2016.05.003] [PMID]

[37] Tracy JL, Robins RW. Putting the self into self-conscious emotions: A theoretical model. Psychological Inquiry. 2004 15(2):103-25. [DOI:10.1207/s15327965pli1502_01]

[38] Tangney JP, Tracy JL. Self-conscious emotions. In: Leary M, Tangney JP, editors. Handbook of Self and Identity. New York City: Guilford Press; 2011.

[39] Baumeister RF, Stillwell AM, Heatherton TF. Guilt: An interpersonal approach.1994; 115(2):243-67. [PMID]

[40] Gilbert P, Andrews B. Shame: Interpersonal behavior, psychopathology, and culture. Oxford: Oxford University Press; 1988.

[41] Saini M, Stoddart KP, Gibson M, Morris R, Barrett D, Muskat $\mathrm{B}$, et al. Couple relationships among parents of children and adolescents with autism spectrum disorder: Findings from a scoping review of the literature. Research in Autism Spectrum Disorders. 2015; 17(1):142-57.

[42] Hart D, Matsuba MK. The development of pride and moral life. In: Tracy JL, Robins RW, Tangney JP, editors. The Self-Conscious Emotions: Theory and Research. New York City: Guilford Press; 2007.

[43] TracyJL,ShariffAF,ChengJT.Anaturalist'sview of pride.Emotion Review. 2010; 2(2):163-77. [DOI:10.1177/1754073909354627]

[44] Kaufman G. The psychology of shame: Theory and treatment of shame-based syndromes. New York City: Springer; 2004

[45] Bruno S, Lutwak N, Agin MA. Conceptualizations of guilt and the corresponding relationships to emotional ambivalence, selfdisclosure, loneliness and alienation. Personality and Individual Differences. 2009; 47(5):487-91. [DOI:10.1016/j.paid.2009.04.023] 